\title{
Erratum to: The Conceptual Model and Guiding Principles of a Supported-Education Program for Orthodox Jewish Persons with Severe Mental Illness
}

\author{
Ron Shor · Guy Avihod
}

Published online: 1 March 2011

(C) Springer Science+Business Media, LLC 2011

Erratum to: Community Ment Health J

DOI 10.1007/s10597-011-9387-8

Unfortunately family name of the second author spelled incorrectly. Avihod has to be spelt out like this and it is not Aivhod as published.

The online version of the original article can be found under doi:10.1007/s10597-011-9387-8.

R. Shor $(\bowtie)$

School of Social Work and Social Welfare, The Hebrew

University of Jerusalem, Mt. Scopus, Jerusalem, Israel

e-mail: msshor@mscc.huji.ac.il

G. Avihod

Rehabilitative Beit Midrash, Jerusalem, Israel

e-mail: avihod@gmail.com 